\title{
Improvement in Corrosion Resistance of Aluminium Alloy by Permanganate-based Conversion Coating
}

\author{
Makanjuola Oki, ${ }^{*}$ Adeolu Adesoji Adediran, Bamidele Ogunsemi, Olayinka Oluwole \\ Agboola, Saheed Olayinka and Oyeyemi Ogunsola \\ Department of Mechanical Engineering, Landmark University, PMB 1001, \\ Omu-Aran 251101, Kwara State, Nigeria \\ *Corresponding author: makanjuola.oki@lmu.edu.ng
}

Published online: 25 August 2018

To cite this article: Oki, M. et al. (2018). Improvement in corrosion resistance of aluminium alloy by permanganate-based conversion coating. J. Phys. Sci., 29(2), 13-24, https://doi. org/10.21315/jps2018.29.2.2

To link to this article: https://doi.org/10.21315/jps2018.29.2.2

\begin{abstract}
This investigation on permanganate-based conversion coating describes a chromate-free coating and efforts at reducing the environmental foot prints of metal finishing industries. A golden coloured coating on aluminium specimen was obtained from the permanganate coating $(P M C)$ bath with nominal pH of 7.9. Results from scanning electron microscopy (SEM) examination showed that the conversion coatings are continuous, and the surfaces of the specimens treated in the coating bath are composed of irregularly shaped and mud-cracked coating materials. The coatings, as revealed from energy dispersive spectroscopy (EDX) analyses in the SEM are composed essentially of aluminium, oxygen and manganese compounds which are likely to be hydrated. Accelerated corrosion tests in near neutral 3.5\% sodium chloride solution and natural exposure tests revealed that the replacement of chromate with permanganate improved paint adhesion and corrosion resistance on aluminium substrates. Furthermore, the results indicated that the corrosion resistance of the permanganate-based conversion coating matched those from the traditional chromate coating bath, but for the corrosion resistance, after application of a top coat of lacquer, the former was adjudged better than the later.
\end{abstract}

Keywords: Aluminium, permanganate, corrosion resistance, conversion coating, corrosion 


\section{INTRODUCTION}

Aluminium and its alloys usually carry air-formed thin oxide layer with inherent corrosion resistance to mild environments despite having flawed regions. However, in some instances, such as in the aircraft and building industries, it is usually beneficial to replace the oxide layer with inert, more corrosion resistant conversion coatings. In the past few decades, chromate conversion coatings (CCCs) which impart superior corrosion resistance and improve paint adhesion on aluminium among other characteristics, have been the choice of the metal finishing industries. Chromates have been classified as carcinogens and efforts in finding their replacements in traditional metal pretreatment baths have received much attention in recent times. While some researchers have attempted to replace chromates with zirconium, vanadium, molybdenum, cerium and permanganate, others have tried the sol-gel route with siloxanol, alkoxysilane and aluminium doped solgel materials. ${ }^{1-13}$ Most results obtained from these research works pointed to the direction of inferiority in corrosion resistances of these substitutes, whereas their paint adhesion characteristics have been described as good as those of chromates.

The mechanisms of formation of the coatings through the sol-gel route have been succinctly described by Osborne. ${ }^{14}$ However, the mechanisms of chromate conversion coating formation in the presence of fluoride species in the coating bath is thought to involve the activation of aluminium surface prior to deposition of coating materials through reduction of $\mathrm{Cr}(\mathrm{VI})$ ions in solution to $\mathrm{Cr}(\mathrm{III})$ ions, and subsequent deposition of $\mathrm{Cr}$ (III) hydroxide/oxides as the major components of the coating. However, some aluminium and $\mathrm{Cr}(\mathrm{VI})$ compounds, probably hydrated, were incorporated in the coating as well. ${ }^{15-17}$ The formation of conversion coatings on aluminium from permanganate solution probably follows similar routes as those of the chromate coatings since fluoride species in solution are known etchants of aluminium and manganese can exist in various oxidation states. Thus, in the presence of an activator like fluoride and a species that can exist in more than one oxidation state, the combination was thought to be ripe for formation of a conversion coating on aluminium. This is in agreement with the findings of Yoganandan et al. and Wang et al. that separately concluded that permanganate coatings are composed of metal-oxides, $\mathrm{MnO}_{2}, \mathrm{Mn}_{3} \mathrm{O}_{4}$ and $\mathrm{Mn}_{2} \mathrm{O}_{3}$, etc., as detected by XRD and XPS, respectively. ${ }^{8,18}$ They further suggested that the coatings have superior corrosion resistance to "bare" aluminium in 3.5\% $\mathrm{NaCl}$ solution. With these at the background, the present investigation seeks to know the morphology of any coating formed on aluminium from the permanganate solution and examine its corrosion resistance with reference to a standard chromate coating employed in the aluminium coil coating industry. 


\section{EXPERIMENTAL}

\subsection{Surface Preparation of Substrates}

All chemicals used were of laboratory grade obtained from British Drug Houses Chemicals Ltd., Poole, UK. Samples of aluminium alloy 6000 series obtained from first Aluminium Plc, Nigeria were made out into spade-like electrodes with approximate dimensions of $30 \mathrm{~mm} \times 20 \mathrm{~mm} \times 10 \mathrm{~mm}$. The specimens were cleaned in $10 \% \mathrm{NaOH}$ solution for $5 \mathrm{~min}$, rinsed in water prior to de-smutting in $50 \% \mathrm{w} / \mathrm{w}$ nitric acid solution for $5 \mathrm{~min}$. After rinsing in water, the specimens were allowed to dry in air at room temperature.

\subsection{Conversion Coating Formation}

The conversion coating solution was prepared by mixing $4.0 \mathrm{~g} \mathrm{l}^{-1}$ of potassium permanganate and $1 \mathrm{~g} \mathrm{l}^{-1}$ of sodium fluoride in a 11 flask. The $\mathrm{pH}$ of the coating solution was 7.92 as determined by JENWAY, Model $3505 \mathrm{pH}$ Meter. Coating procedure was by dipping clean and drying pre-weighed aluminium specimens in $100 \mathrm{ml}$ of coating solution for various times ranging from $30 \mathrm{~s}$ to $10 \mathrm{~min}$. After each period of immersion, the specimens were rinsed in water and dried for about $30 \mathrm{~min}$ at room temperature prior to obtaining the weights of the coated specimens. The average changes in weights of five specimens individually treated for the various times employed to determine the rates of development of the coatings were recorded against time. Also, the progress of colour changes was monitored and recorded by photography. Similarly, a chromate conversion coating solution, prepared in the usual manner was employed to coat various aluminium specimens for various times with an average of five changes in coating weights and colours recorded against time. ${ }^{19}$

\subsection{Coating Morphology and Composition}

Five separate specimens treated for various times in both coating solutions were examined in scanning electron microscope (SEM), Phenom proX SEM, model MVE0224651193, operated at $15 \mathrm{KeV}$ and their elemental compositions obtained from the energy-dispersive X-ray (EDX) attachment in the microscope. The coating development was likewise monitored through optical microscope of limited resolution. 


\subsection{Corrosion and Adhesion Tests}

Five specimens coated for $180 \mathrm{~s}$ in the coating solutions were exposed to the tropical, savanna environment in Kwara State of Nigeria for about $500 \mathrm{~h}$ with five untreated aluminium specimens serving as control. The specimens were examined daily, and the progress of exposure test was monitored by visual inspection and optical microscopy. Specimens treated in the coating solutions for $180 \mathrm{~s}$ were further coated with a nitrocellulose lacquer by immersing the aluminium specimens as near vertical as possible in $100 \mathrm{ml}$ of the lacquer for $60 \mathrm{~s}$ and withdrawn as immersed, allowed to dry for $24 \mathrm{~h}$ prior to further examination. Untreated aluminium specimens, specimens treated in the coating solutions, and those over coated with lacquer were cross-scratched prior to exposure to near neutral 3.5\% $\mathrm{NaCl}$ solution for $168 \mathrm{~h}$. After the exposure period and in accordance with Japanese industrial testing method, transparent cellophane adhesive tapes were firmly applied on each of the specimens..$^{20}$ The tapes were subsequently rapidly pulled from the substrates. The surfaces were examined to appraise the mode(s) of coating failure by optical microscopy and in the SEM with analyses performed in the EDX attachment of the SEM.

\section{RESULTS AND DISCUSSION}

\subsection{Coating Development}

The coating growth pattern in both permanganate and chromate solutions are similar. The colours changed from metallic aluminium substrate progressively from light yellow to golden colouration after $3 \mathrm{~min}$ of treatment in both solutions. These are indicative of coating formation and development. The colour of the specimens changed to dark yellowish brown after 10 min of treatment which further showed that interactions between the already formed coating and the coating solutions were dynamic with formation of coating materials either by adsorption/absorption and reaction of coating solution materials with the substrate through pathways that may have developed within the coating. ${ }^{19,20}$ The rates of coating development in both permanganate and chromate solutions are displayed in Figure 1 where it can be observed that the coatings developed rapidly initially with rates that decreased with time of immersion in the coating solutions. These were expected since the initially formed coating materials will restrict further interaction of the coating solution species with the substrate. These observations are also supported by the findings of Hughes et al. who observed increase in Mn content of PCC with time although the coating remained stunted at about $70 \mathrm{~nm}$ in thickness. ${ }^{21}$ 


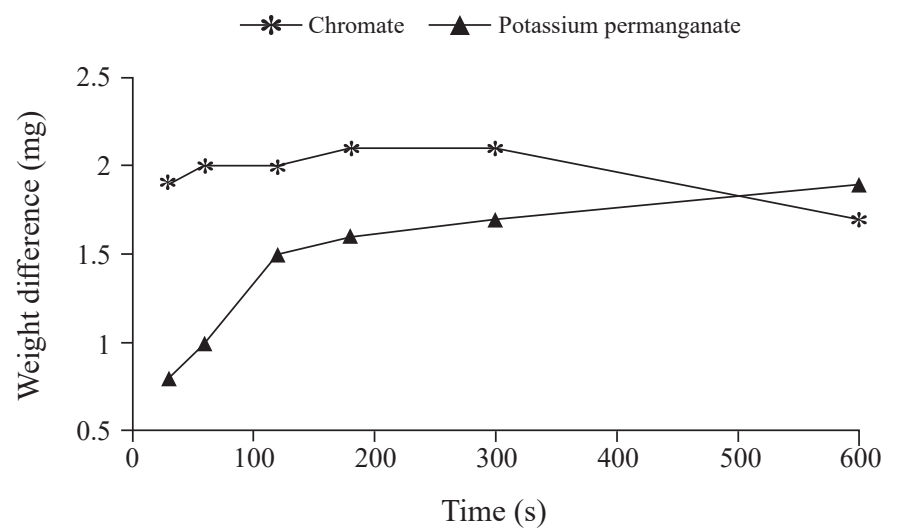

Figure 1: Weight change of aluminium specimens with time of immersion in permanganate and chromate conversion coating baths.

However, further development of the coating although at a slower rate might have continued with the formation of pathways within the coating. ${ }^{17,22}$ The rate of development of the chromate coating was faster than for the permanganate which was expected as the chromate bath was acidic, and the permanganate was a nearneutral coating solution. The maximum weight attained in the chromate bath was about $2 \mathrm{mg}$ whereas for the permanganate coating, it was about $1.8 \mathrm{mg}$. These were attained over a protracted treatment time of $600 \mathrm{~s}$ which was as a result of the reduction in the rate of change in weights of the coatings due to weathering occasioned by the aggressive coating baths.

\subsection{Surface Morphology and Composition of Permanganate Conversion Coating}

The development, morphology and corrosion resistance of CCCs on aluminium have been described by various authors as characterised by mud-cracked morphology and are presently considered to have superior corrosion resistance and improved paint adhesion over their contemporaries. ${ }^{19-24}$ However, SEM examinations revealed that the morphologies of all specimens treated for various times in the permanganate solution appeared similar. A typical example is displayed in Figure 2( $a$ and $b$ ), where light and dark randomly shaped materials of various sizes can be observed in a matrix of cracked coating materials. Such micro-roughness at the coating/solution interface may contribute to colour changes in the coatings from light yellow to golden yellow colouration with increases in immersion times of the specimens. In addition, increases in coating thickness with the formation of coating materials as well as uptake in coating solution species as described elsewhere and by others may contribute to the gradual colour changes. ${ }^{8,15,21,25}$ 


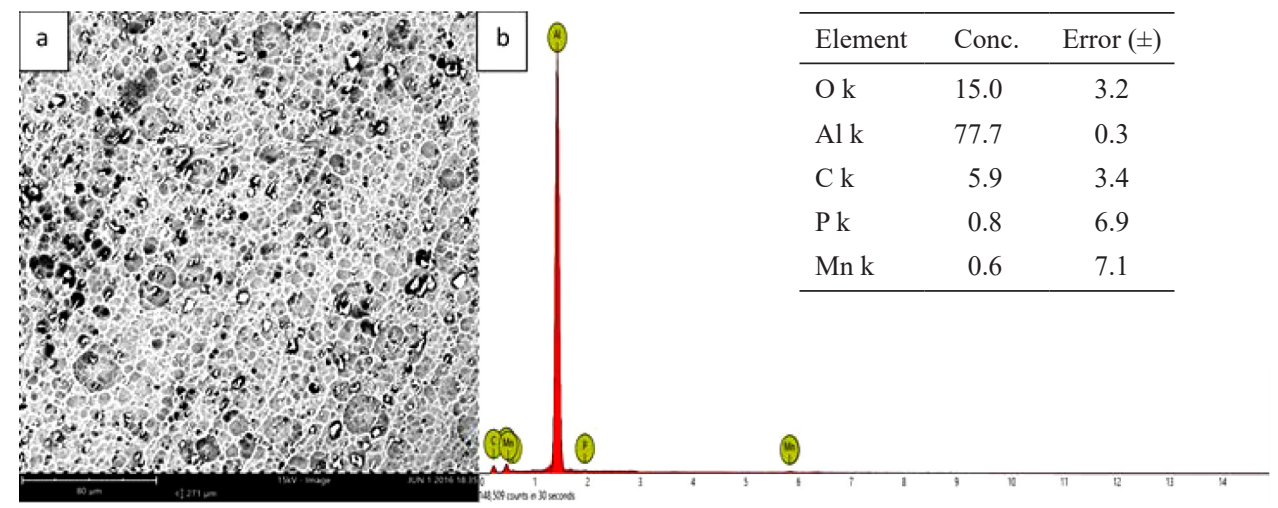

Figure 2: SEM and EDX of the specimen treated for $180 \mathrm{~s}$ in permanganate conversion coating solution at $30^{\circ} \mathrm{C}$.

The cracks may have developed as a result of shrinkage stresses normally observed in drying out gel-like materials. These coating features, which are characteristic of all specimens treated for $30 \mathrm{~s}$ to $600 \mathrm{~s}$, may have developed in a manner that mapped the grain and sub-grain boundaries of the substrate aluminium as described by Oki and Charles. ${ }^{22}$ It is generally known that grain boundaries are anodic to the interior of grains; also it has been shown by various authors that fluorides in conversion coating baths activate aluminium with the release of 3 electrons, thus: ${ }^{26}$

$$
\mathrm{Al} \rightarrow \mathrm{Al}^{3+}+3 \mathrm{e}^{-}
$$

The electrons released in the anodic reaction (Equation 1) will be taken up in the cathodic half of the redox reaction which will predominantly take place within the grains and impurities in the substrate with the deposition of the coating materials when their solubility constants are attained. For the permanganate coating bath, at near-neutral $\mathrm{pH}$ regime, the most favourable cathodic reaction will be:

$$
2 \mathrm{H}_{2} \mathrm{O}+\mathrm{MnO}_{4}^{-}+3 \mathrm{e}^{-} \rightarrow \mathrm{MnO}_{2}+4 \mathrm{OH}^{-}
$$

Thus, $\mathrm{MnO}_{2}$ will form the bulk of the coating materials with aluminium oxides/ hydroxides deposited along with it while $\mathrm{MnO}_{4}^{-}$may be adsorbed/occluded within the growing coating materials. ${ }^{27,28}$ The predicted mechanism of formation agreed with the elemental compositions obtained from EDX analysis displayed in Figure 2(b) and supported by the findings of Yoganandan et al. and Wang et al. ${ }^{8,18}$

Although most researchers agree with Equation 1, Thompson suggested that thinning of the oxide skin on aluminium occurs with formation of aluminium ions which are further re-oxidised to $\mathrm{Al}_{2} \mathrm{O}_{3}$ formed the basic anodic reaction. ${ }^{23}$ The oxide layer, very much thinner than the original $2.5 \mathrm{~nm}$ as described separately by 
Pokorny et al. and Thompson, allowed electron tunnelling for subsequent cathodic reactions to take place as described in Equation 2. ${ }^{19,22,23}$

The elemental compositions of the coating as revealed by the EDX analysis are $\mathrm{Al}, \mathrm{Mn}, \mathrm{O}$ and C. Although EDX does not give quantitative analysis of elements present in a given sample, it was observed that signals for the coating components increased in height as the time of treatment of specimens increased in the coating bath in a similar manner observed by various other authors. ${ }^{15,19,21,25}$ The EDX yield for aluminium is large, however, this is a result of X-rays generated from the substrates as well as from within the coating. Other observed peaks must have been generated from within the coating/residual impulses from within the equipment. Higher yields for Mn, as depicted in Figure 3, were observed when spot analyses were performed on the white, randomly shaped materials with a population density of about $3 \times 10^{10} \mathrm{~m}^{-2}$ on the surface of the coating displayed in Figure 2. These showed an enrichment of $\mathrm{Mn}$ at specific regions of the coating probably with iron inclusions as an intermetallic which are normally cathodic to the aluminium matrix..$^{29,30}$

The compositional analysis obtained by other authors using various analytical tools agree with the findings in this investigation that permanganate conversion coating is essentially composed of $\mathrm{MnO}_{2}$ and $\mathrm{Al}_{2} \mathrm{O}_{3} /(\mathrm{OH})_{3}$ which are probably hydrated..$^{8,18,21}$

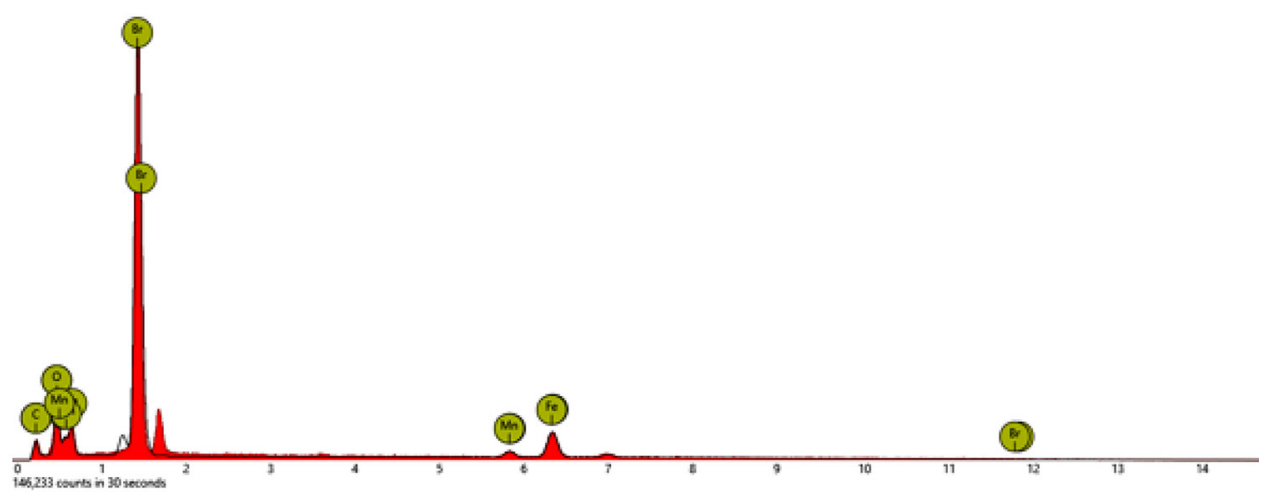

Figure 3: EDX spot analysis at light coloured coating materials on specimen treated for $180 \mathrm{~s}$ in permanganate coating bath at $30^{\circ} \mathrm{C}$.

\subsection{Corrosion and Adhesion}

Conversion coated specimens, without a top coating of lacquer, during atmospheric exposure tests gradually faded in colour to a lighter shade of golden yellow whereas bare aluminium, similarly exposed developed mounds of corrosion 
products, aluminium oxide/hydroxide were also observed on the lacquer coated bare aluminium specimens after the exposure time of $500 \mathrm{~h}$ (a representative micrograph is presented in Figure 4).

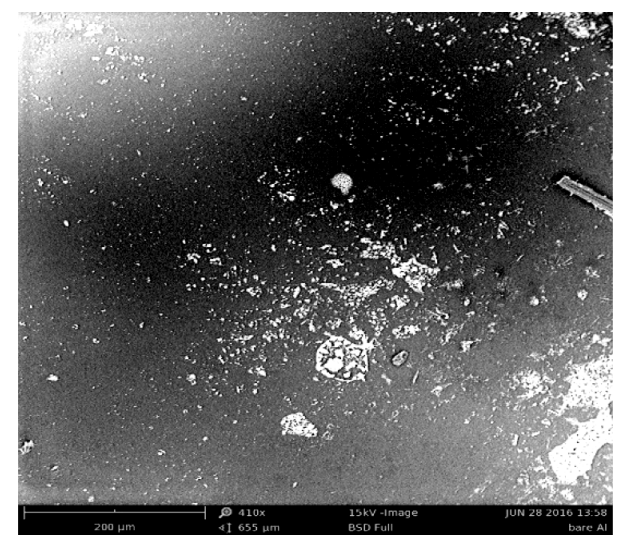

Figure 4: Lacquer coated bare aluminium after exposure for $500 \mathrm{~h}$ in $3.5 \%$ sodium chloride solution.

The corrosion products were visible to the naked eyes under the top lacquer coating applied prior to atmospheric exposure. However, the specimens with conversion coatings and top coating of lacquer performed creditably well as revealed during optical microscopy examinations.

Figures 5 displays the optical photographs for chromate and permanganate conversion coated specimens with top coatings of lacquer after exposure for $168 \mathrm{~h}$ in near-neutral 3.5\%.
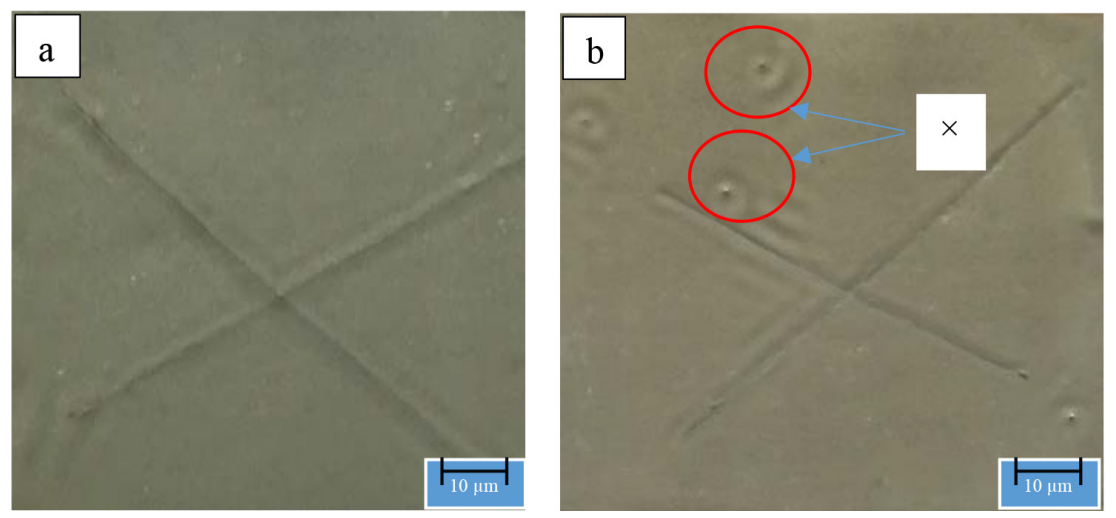

Figure 5: Lacquer coated with (a) chromate and (b) permanganate conversion coated aluminium specimens after exposure for $168 \mathrm{~h}$ in $3.5 \%$ sodium chloride solution. 
Sodium chloride solution where the superiority of the former over the latter can be vividly observed. The permanganate specimen showed some signs of pitting corrosion at various regions marked " $\mathrm{X}$ " in Figure 5(b), while the chromate portrayed a surface without any sign of corrosion. However, it is worthy of note that the untreated, lacquer coated counterpart showed paint delamination, whereas for the two conversion coated specimens, paint delamination was not observed and the lacquer was not peeled off after application of adhesion tests. ${ }^{20}$ For those specimens without a top coating of lacquer but similarly treated in conversion coating baths prior to exposure in $3.5 \%$ sodium chloride solution, apart from gradual fading in colour, pitting corrosion was not observed on the specimens. It has been observed by other researchers that there are leachable $\mathrm{Cr}^{6+}$ species in chromate conversion coatings which serve as corrosion inhibitors at transiently exposed regions of aluminium substrate. ${ }^{14,24,31}$ It is likely that leachable $\mathrm{MnO}_{4}{ }^{-}$species are present in the permanganate coating and these can be reduced at corroding sites of the substrate to plug any corrosion reaction in such regions as with the use of XPS, $\mathrm{KMnO}_{4}$ as was detected in PCC by Yoganandan et al. ${ }^{8}$ The specimen immersed in $3.5 \% \mathrm{NaCl}$ but initially treated in permanganate coating solution carrying a top coating of lacquer was further examined with SEM. As displayed in Figure 6, there was no paint delamination and the lacquer did not peel off after the application of adhesive tests. ${ }^{20}$

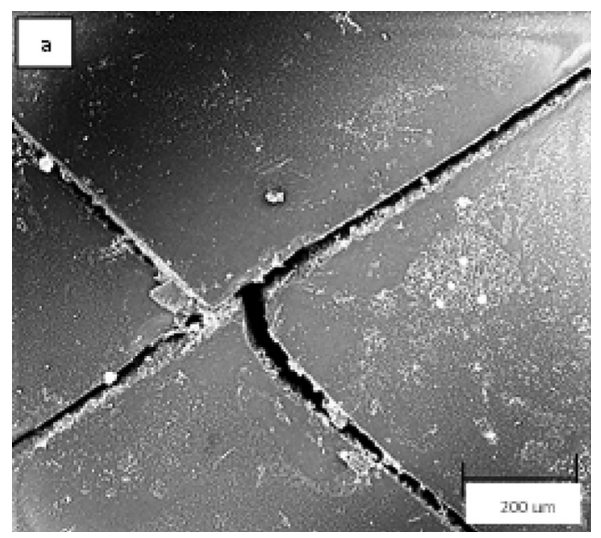

Figure 6: SEM of permanganate treated aluminium specimen with a top coating of lacquer after exposure to $3.5 \%$ sodium chloride solution for $168 \mathrm{~h}$.

\section{CONCLUSION}

Improvement in corrosion resistance of aluminium alloy by permanganate-based conversion coating has been investigated. The results obtained within the detection limits of EDX revealed that the permanganate coating is composed of manganese, 
aluminium and oxygen compounds, which were probably hydrated. The atmospheric corrosion protection and paint adhesion characteristics of the permanganate coating compared favourably well with those of chromate conversion coating. However, with the exposure of lacquer coated specimens to sodium chloride solution, pitting corrosion resistance of chromate conversion coating was found to be superior to those of permanganate-based conversion coating. They both performed better than bare aluminium alloy specimens.

\section{ACKNOWLEDGEMENTS}

The authors acknowledge the Department of Mechanical Engineering, Covenant University, Ota, Ogun State, Nigeria, for the use of SEM/EDX facilities.

\section{REFERENCES}

1. Asemani, H. R. et al. (2016). Effect of zirconium conversion coating: Adhesion and anti-corrosion properties of epoxy organic coating containing zinc aluminum polyphosphate (ZAPP) pigment on carbon mild steel. Prog. Org. Coat., 94, 18-27, https://doi.org/10.1016/j.porgcoat.2016.01.015.

2. Oki, M. (2007). Studies on chromium-free conversion coatings on aluminium. J. App. Sci. Environ. Manage., 11(2), 187-190.

3. Morris, E. L. (2014). Corrosion resistant coating compositions. US Patent 235317, filed 16 September 2011, issued 28 March 2013.

4. Wang, C., Feng, J. \& Haichao, L. (2003). The molybdate conversion coatings on LY12 aluminum alloy. Rare Met. Mater. Eng., 32(199), 130-133.

5. Liang, C. S. et al. (2014). Molybdate-based conversion treatment for improving the peeling strength between aluminum foil and polypropylene grafted with glycidyl methacrylate. Surf. Coat. Tech., 249, 1-5, https://doi. org/10.1016/j.surfcoat.2014.03.038.

6. Joshi, S. et al. (2011). Characterization of cerium-based conversion coatings on Al 7075-T6 deposited from chloride and nitrate salt solutions. J. Electrochem. Soc., 158(3), 88-93, https://doi.org/10.1149/1.3537821.

7. Lin, C. et al. (2012). Deposition of cerium-based conversion coatings on aluminum alloy 380. Int. J. Corr., Article ID 760284, 1-9, https://doi. org/10.1155/2012/760284.

8. Yoganandan, G., Balaraju, J. N. \& William Grips, V. K. (2012). The surface and electrochemical analysis of permanganate based conversion coating on alclad and unclad 2024 alloy. Appl. Surf. Sci., 258(22), 8880-8888, https://doi.org/10.1016/j.apsusc.2012.05.108. 
9. Morris, E. L., Jane, A. N. \& Kim, K. (2014). Permanganate based conversion coating compositions. US Patent WO/2014/186286, filed 12 May 2014, issued 20 November 2014.

10. Jian, S. Y., Chu, Y. R. \& Lin, C. S. (2015). Permanganate conversion coating on an AZ31 magnesium alloys with enhanced corrosion resistance. Corros. Sci., 93, 301-309, https://doi.org/10.1016/j.corsci.2015.01.040.

11. Gonzalez, E. et al. (2011). Silanol-based nanocomposite coating for protection of AA-2024 aluminium alloy. Electrochim. Acta., 56, 7585-7595, https://doi.org/10.1016/j.electacta.2011.06.082.

12. Zheludkevich, M. L., Salvado, I. M. \& Ferreira, M. G. S. (2005). Sol-gel coatings for corrosion protection of metals. J. Mater. Chem., 15, 5099-5111, https://doi.org/10.1039/b419153f.

13. Oubaha, M. et al. (2014). Development of a novel hybrid aluminum-based sol-gel materials: Application to the protection of AA2024-T3 alloys in alkaline environment. Adv. Mater. Phy. Chem., 4, 75-84, https://doi. org/10.4236/ampc.2014.45010.

14. Osborne, J. H. (2001). Observations on chromate conversion coatings from a sol-gel perspective. Prog. Org. Coat., 41, 280-286, https://doi.org/10.1016/ S0300-9440(01)00143-6.

15. Oki, M., Oki, T. K. \& Charles, E. (2012). Chromate and chromate phosphate conversion coatings on aluminium. Arab. J. Sci. Eng., 37, 59-64, https://doi. org/10.1007/s13369-011-0157-2.

16. Liu, Y. et al. (2004). Chromate conversion coating on aluminum: Influences of alloying. Corros. Sci., 46, 293-299, https://doi.org/10.1016/S0010938X(03)00157-4.

17. Zhu, W. et al. (2017). Comparative study on $\mathrm{Ti} / \mathrm{Zr} / \mathrm{V}$ and chromate conversion treated aluminum alloys: Anti-corrosion performance and epoxy coating adhesion properties. Appl. Surf. Sci., 405, 157-168, https://doi.org/10.1016/j.apsusc.2017.02.046.

18. Guixiang, W., Milin, Z. \& Ruizhi, W. (2012). Molybdate and molybdate/ permanganate conversion coatings on Mg-8.5Li alloy. Appl. Surf. Sci., 258(7), 2648-2654, https://doi.org/10.1016/j.apsusc.2011.10.112.

19. Pokorny, P., Tej, P. \& Szelag, P. (2016). Chromate conversion coatings and their current application. Metal., 55(2), 253-256.

20. Japanese Standards Association. (1990). Japanese industrial standard testing methods for paints JISK 5400. Tokyo: Japanese Standards Association.

21. Hughes, A. E. et al. (2006). Development of permanganate-based coatings on Al alloy 2024-T3. Corros. Sci., 62(9), 773-780, https://doi. org/10.5006/1.3278302.

22. Oki, M. \& Charles, E. (2009). Chromate conversion coating on $\mathrm{Al} / 0.2 \% \mathrm{Fe}$. Mater. Lett., 63, 1990-1991, https://doi.org/10.1016/j.matlet.2009.06.033. 
23. Thomson, G. E. (1994). Conversion coatings. TALAT Lecture series 5202, European Alumni Association, 1-9.

24. Oki, M. (2013). Corrosion of aluminium in chloride environments. Int. J. Pure App. Chem., 32(2), 147-158, https://doi.org/10.9734/IRJPAC/2013/2946.

25. Oki, M. (2013). Microstructural and compositional characterization of chromate pretreatment on Aluminium. Mater. Sci., Article ID 572379, https://doi.org/10.115/2013/572379.

26. Zhang, C. et al. (2016). Preparation of a self-developed chrome-free colored coating based on a titanium conversion coating on $6063 \mathrm{Al}$ alloy. RSC Adv., 6, 62045-62051, https://doi.org/10.1039/C6RA11634E.

27. Kulinich, S. A., Farzaneh, M. \& Du, X. W. (2007). Growth of corrosionresistant manganese oxide coatings on an aluminum alloy. Inorg. Mater., 43(9), 956-963, https://doi.org/10.1134/S0020168507090087.

28. Yu, F. et al. (2015). The mechanism of solution acidification during chemical conversion process on aluminium alloys. Mater. Res. Innov., 19(2), 28-34, https://doi.org/10.1179/1432891715Z.0000000001310.

29. Kolics, A., Besing, A. S. \& Wieckowski, A. (2001). Interaction of chromate ions with surface intermetallics on aluminum alloy 2024-T3 in NaCl solutions. J. Electrochem. Soc., 148(8), 322-331, https://doi.org/10.1149/1.1380674.

30. Lunder, O. et al. (2005). Formation and characterization of a chromate conversion coating on AA6060 aluminium. Corros. Sci., 47, 1604-1624, https://doi.org/10.1016/j.corsci.2004.08.012.

31. Grilli, R. et al. (2011). Corrosion behaviour of a 2219 aluminium alloy treated with a chromate conversion coating exposed to a $3.5 \% \mathrm{NaCl}$ solution. Corros. Sci., 53, 1214-1223, https://doi.org/10.1016/j.corsci.2010.12.006. 